Refereed version forthcoming in Journal of Business Research (ISSN 0148-2963)

\title{
The moderating role of cultural intelligence in the relationship between cultural orientations and conflict management styles
}

\author{
Andrea Caputo (Corresponding author) \\ University of Lincoln, Lincoln International Business School \\ Brayford Pool, LN6 7TS Lincoln, UK \\ acaputo@lincoln.ac.uk \\ Oluremi B. Ayoko \\ The University of Queensland, UQ Business School \\ 39 Blair Dr, St Lucia QLD 4067, Australia \\ r.ayoko@business.uq.edu.au \\ Nii Amoo \\ Leeds Business School \\ Leeds Beckett University \\ The Rose Bowl, Portland Gate, LS1 3HB, Leeds, UK \\ n.amoo@leedsbeckett.ac.uk
}

\begin{abstract}
Today's international corporate environments demand that employees are culturally intelligent for effective engagement in cross-cultural interactions. This study examines the moderating effect of cultural intelligence (CQ) in the relationship between individual cultural orientations and the choice of a conflict management style. A sample of 403 employees completed self-report measures of all study variables. Findings confirmed the impact of cultural orientations on conflict management styles, namely avoiding, forcing and problem-solving. Moreover, findings confirm the existence of a moderated effect of some facets of cultural intelligence on the relationship between individual's cultural orientations and conflict management styles. The study offers novel empirical evidence for the important role that cultural intelligence has in managing conflict for increased productivity and performance in diverse international environments.
\end{abstract}

Keywords: cultural intelligence; conflict management; cultural orientation; avoiding; forcing; problemsolving 


\section{The moderating role of cultural intelligence in the relationship between cultural orientations and conflict management styles}

\section{Introduction}

Organizations are becoming increasingly multicultural in their composition and global in their scope. People from different cultural backgrounds are extremely interconnected due to the advancements in telecommunication, technology and free movement of workers, posing serious challenges not only to workplaces but also societies. Such trends have increased diversity in the workplace, especially cultural diversity, impacting the composition, processes and management of work teams (Groves \& Feyerherm, 2011). Research suggests that facilitating cross-cultural interactions in diverse organizations is a challenge (Lin, Chen, \& Song, 2012). While workplace cultural diversity is potentially beneficial (increased innovation, productivity and effective decision making process), it also has the potential to intensify conflicts due to conflicting cultural differences and behaviors (e.g., Ayoko \& Härtel, 2006; Earley \& Gibson, 2002; Mannix \& Neale, 2005).

In organizations employees are often encouraged to address the conflict through various Conflict Management Styles (CMSs) such as avoiding, involving the decision to not engage in the conflict and deliberately avoid its management; forcing, involving competitive and aggressive tactics to manage the conflict where individuals are mostly concerned with their own gain; and problem solving, concerning the cooperative and collaborative motives individuals have when trying to balance their own interests with the others interests (e.g., Thomas, 1992). These CMSs have been identified to influence outcomes, such as job performance (e.g., Alper, Tjosvold, \& Law, 2000; Tjosvold, 2006), leader effectiveness (e.g., Ayoko \& Konrad, 2012), organizational and network success (e.g., Bradford, Stringfellow, \& Weitz, 2004; Celuch, Bantham, \& Kasouf, 2011; X. Lin \& Germain, 1998), and innovation (e.g., Amason \& Schweiger, 1997).

In this study, we build upon the limited literature showing that the choice of styles in managing conflict in culturally diverse organizations is driven by employees' values and cultural orientations (e.g., Gunkel, Schlaegel, \& Taras, 2016; Holt \& DeVore, 2005; Oudenhoven, Mechelse, \& De Dreu, 1998) and 
we investigate the indirect effect of Cultural Intelligence (CQ) on such relationship (See Figure 1). CQ defined as a person's capability to effectively adapt, function and manage, in new culturally diverse environments and situations (Earley \& Ang, 2003) - might improve cross-cultural interactions at work (Templer, Tay, \& Chandrasekar, 2006) and perhaps minimize conflict. This is because by its characteristic, CQ should allow people to interpret unfamiliar and ambiguous gestures as if they were familiar and interact effectively with people who are culturally diverse (Earley, Ang, \& Tan, 2006). Despite the promise of CQ for effective cross-cultural interactions, few studies have investigated the role of CQ in the relationship between cultural orientations and the choice of conflict management styles. We focus on the impact of cultural orientations on three CMSs namely: avoiding, forcing and problem solving, and especially the role of CQ in the link between individuals' cultural orientations and these styles.

Our study makes several theoretical contributions. First, there is evidence that parties who engage in conflict may respond with differing conflict management styles. However, literature is scarce about the connection between individual's cultural orientations and their conflict management styles. Findings from our study should assist in teasing out which cultural orientation impact what aspects of conflict management styles. Second, our research findings should deepen our understanding of the impact of CQ on differing aspects of conflict management styles. Third, through our findings on CQ, we contribute to the growing bodies of literature revisiting the role of individual differences in conflict management. Altogether, outcomes emanating from our research should deepen the researchers and managers' understanding of the connection between cultural values/orientations, CMSs and CQ for a more integrated and effective understanding and handling of conflict within multicultural organizations.

\section{Theoretical Background}

In this study, we follow Hofstede (1980) to describe culture as "the collective programming of the mind that distinguishes the members of one group or category of people from others" (Hofstede, 1980, p. 25). A collective phenomenon, culture resides in more or less conscious values and norms (Hofstede, 2001). Hofstede's $(1980,2001)$ framework consists of five dimensions, all considered to be on a 
continuum ranging between two poles - e.g. an individual lower in masculine culture could be referred to as having feminine culture - power distance (low vs high), uncertainty avoidance (low vs high), individualism vs. collectivism, masculinity vs. femininity, and long-term vs. short-term orientation. We adopted Hofstede framework because it is the cultural framework that is most frequently adopted and replicated by scholars in the context of CMSs (see Aycan \& Gelfand, 2012; Kaushal \& Kwantes, 2006; Kirkman, Lowe, \& Gibson, 2006; Yoo, Donthu, \& Lenartowicz, 2011). However, in agreement with the view that individual differences about general preferences and preferences for managing conflict are culture specific (e.g., Ting-toomey \& Kurogi, 1998; Ting - Toomey, Oetzel, \& Yee - Jung, 2001) and with criticisms about inferring cultural orientations from the Hofstede's studies (Yoo et al., 2011), we decided to measure the cultural orientations directly, instead of measuring through inferences from demographic characteristics.

We broadly define conflict as the situation where parties perceive that their goals or interests are incompatible or in opposition (e.g., Ayoko \& Konrad, 2012). Conflict management refers to the understanding of conflict as a whole, its triggers, the conflict cycle, and the CMSs and behaviors, and the main objective of conflict management is not to eliminate conflict, but to find different ways to manage it properly by controlling the dysfunctional elements of the conflict while facilitating its productive aspects. The dominant model that emerged in the literature to explain the CMSs is the dual concern model (Pruitt \& Rubin, 1986). This framework differentiates the styles of handling conflict according to two distinct dimensions: the concern for self refers to the degree to which a person tries to fulfill and satisfy his or her own interests; and the concern for others refers to the degree to which a person tries to satisfy the interests of the other party. Accordingly, scholars have identified a number of styles that individuals adopts to respond to conflict (e.g., De Dreu, Evers, Beersma, Kluwer, \& Nauta, 2001; Van De Vliert, Euwema, \& Huismans, 1995). In this context, Avoiding occurs when a solution to a conflict is sought by avoiding confrontation with the other party, Forcing occurs when parties try to manage the conflict by 
pushing for their own needs at the expenses of the other; and Problem solving occurs when a solution is sought jointly by taking into considerations the interests of all sides.

Previous research showed that culture impacts individuals' CMSs (see Imai \& Gelfand, 2010; Kaushal \& Kwantes, 2006; Ogliastri \& Quintanilla, 2016; Ting-Toomey et al., 2000), and that conflicts in intercultural exchanges suffer from higher complexity (e.g., Wall \& Callister, 1995), and communication difficulties (e.g., Liu, Chua, \& Stahl, 2010). For example, Gunkel, Schlaegel and Taras (2016) suggest that the choice of styles in managing conflict in culturally diverse organizations is driven by values and cultural orientations (see also Holt \& DeVore, 2005; Oudenhoven, Mechelse, \& Dreu, 1998).

There are suggestions that successful interaction across cultures requires cultural intelligence (CQ), defined as a "person's capability for successful adaptation to new cultural settings" (Earley \& Ang, 2003, p. 7). CQ has been studied within several domains, such as team work (Adair, Hideg, \& Spence, 2013), decision-making (Ang et al., 2007), leadership (Groves \& Feyerherm, 2011), expatriates management (Kim, Kirkman, \& Chen, 2008; Vlajčić, Caputo, Marzi, \& Dabić, 2018) and negotiation (Groves, Feyerherm, \& Gu, 2015; Imai \& Gelfand, 2010). Surprisingly, conflict management literature has given a scarce attention to the topic. Yet, we know that given the characteristic features of conflict, the ability to effectively manage conflict is critical especially in multicultural contexts.

CQ is conceptualized as a multifaceted variable consisting of four elements (Earley \& Ang, 2003). Metacognitive $C Q$ refers to the conscious awareness that an individual has regarding cultural interactions, as well as the ability to strategize when crossing cultures and to carefully ascertain personal thoughts and the thoughts of others. Cognitive $C Q$ reflects the knowledge of a group's values, beliefs, and norms, and the understanding of culture and its role in determining the style of doing business and interacting with others across different cultures. Motivational $C Q$ reflects the capability to direct energy toward learning about cultural differences, i.e. the interest, drive, and energy invested in cross-cultural adaptations while Behavioral $C Q$ reflects the ability to choose appropriate verbal and physical actions when interacting with people of different cultures, it is the ability to act appropriately amid cross-cultural issues. Culturally intelligent individuals can better understand a cultural difference and adapt their 
behavior to fit in the different culture. This adaptation should result in not only feeling accepted but also acceptance of others. The feelings that accompany acceptability by individuals from various cultures during interaction can foster effective interactions by easing the boundaries of cultural differences.

Therefore, in the next section we present our hypothesized model that explains how the impact of cultural orientations on CMSs is moderated by cultural intelligence.

Figure 1 - Theoretical Model

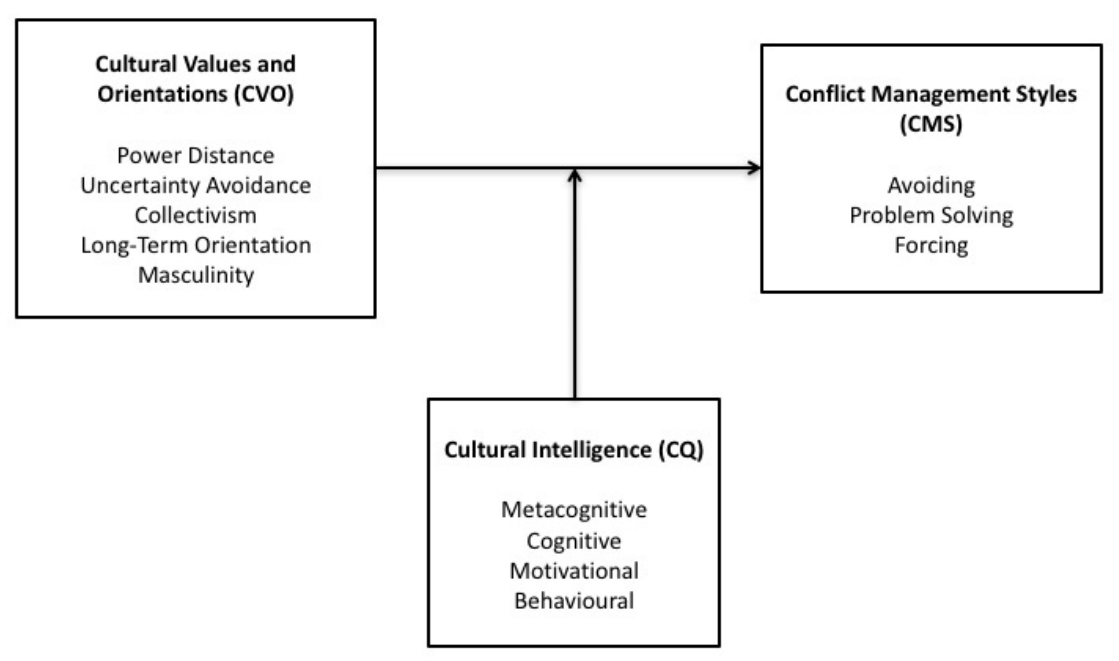




\section{Hypotheses development}

According to the Hofstede's classification, power distance relates to the different solutions to the basic problem of human inequality, and it has been defined as "the extent to which the less powerful members of organizations and institutions accept and expect that power is distributed unequally" (Hofstede, 2011, p. 9). In low power distance cultures (or for people with low power distance) equality and opportunities for everyone are considered important. For example, the use of power is expected to be legitimate and subject to ethical criteria, hierarchies are perceived as means of inequality and consequently subordinates are expected to be consulted. Conversely, for people adhering to high power distance, power is considered to be a basic fact of society, regardless of legitimacy and ethics, hierarchy is conceived as an existential inequality, and subordinates are expected to be told what to do (Hofstede, 2011).

In terms of power distance and the preferences for CMSs, Oudenhoven et al. (1998) found power distance positively related to problem solving. Others have found power distance to be positively to avoiding and forcing styles (Kim, Wang, Kondo, \& Kim, 2007; Purohit \& Simmers, 2006). As power distance relates to different behaviors depending on if one is in power or under power, the differences in results might be related to differences in the status of respondents and cultural homogeneity of the samples used. It was explained that individuals with a higher power distance, but not in power positions, tend to be less competitive and confrontational in solving interpersonal conflict with their supervisors (Kim et al., 2007), while individuals holding power tend to be more competitive (Purohit \& Simmers, 2006). More recently, results from the comparison of ten cultural clusters showed that power distance was positively and significantly related with an avoiding style as well as with a forcing style (Gunkel et al., 2016).

Thus, we expect that individuals with a higher degree of power distance are more likely to adopt forcing and avoiding as a response to conflict. Specifically, we expect that in high power distance cultures, individuals with power (e.g. higher status) would most likely employ forcing because it allows 
the powerful to operationalize and maintain their power over the weak. In contrast, the lower status individuals will most likely employ avoidance in the face of conflict.

Hla: Individuals high in power distance are positively related to the avoiding style.

H1b: Individuals high in power distance are positively related to the forcing style.

H1c: Individuals high in power distance are negatively related to the problem-solving style.

Uncertainty avoidance relates to the level of stress in a society in the face of an unknown future, i.e. a society's tolerance for ambiguity (Hofstede, 2001). Individuals who express low values of uncertainty avoidance tend to accept uncertainty in their lives, they tend to perceive lower stress and anxiety, tolerable for deviant persons and ideas, dislike rules and are not afraid of changing jobs. On the contrary, individuals with higher levels of uncertainty avoidance tend to perceive life as continuously threatened by uncertainty, feel higher levels of stress and anxiety, and express a need for clarity and structure (Hofstede, 2001).

In terms of uncertainty avoidance and the preferences for CMSs, Purohit and Simmers (2006) showed that uncertainty avoidance was positively related to forcing and avoiding, and Oudenhoven et al. (1998) found that individuals from more uncertainty avoiding cultures were negatively related to the problem solving style. Finally, Gunkel et al. (2016) reported that uncertainty avoidance was positively related to both problem-solving and avoiding. The contradicting results of these previous studies suffer from limitations due to the cultural homogeneity of their sample, the presumed culture based on participants' nationality and the use of students. Based on such findings, we argue that individuals with higher levels of uncertainty avoidance will tend to respond to conflict either with a less engaging style, such as avoiding, or, when engaging, with a cooperative style, such as problem solving. This is because individuals with high uncertainty avoidance will tend to circumvent the uncertain surrounding the conflict situation. To limit the uncertain, such individuals will either recur to the avoidance of the conflicting situation, which will lead them to perceive a reduce conflict, or to cooperate with the other party to get more clarity around the uncertainty surrounding the conflict. 
H2a: Individuals high in uncertainty avoidance are positively related to the avoiding style.

H2b: Individuals high in uncertainty avoidance are negatively related to the forcing style.

H2c: Individuals high in uncertainty avoidance are positively related to the problem-solving style.

Collectivism vs individualism relates to the integration of individuals into primary groups (Hofstede, 2011). Individuals with strong collectivistic values tend to expect that harmony should always be maintained, however, in-group members tend to be favored over the out-group members and opinions are mostly predetermined by in-group dynamics. A recent meta-analysis showed a strong evidence for differences in CMSs based on collectivism vs individualism (Holt \& DeVore, 2005). In particular, research has shown that individuals adhering to collectivist cultures tend to prefer avoiding and problem solving styles of conflict management over the others (Holt \& DeVore, 2005; Ting-Toomey et al., 1991). Conversely, individualists tend to prefer mostly the forcing styles (Holt \& DeVore, 2005). Gunkel et al. (2016) confirmed that collectivism positively related to problem solving and negatively related to forcing. H3a: Individuals high in collectivism are positively related to the avoiding style.

H3b: Individuals high in collectivism are negatively related to the forcing styles.

H3c: Individuals high in collectivism are positively related to the problem-solving style.

Masculinity, as opposed to femininity, relates to the division of emotional roles between women and men. The research from Hofstede $(1980,2001)$ identified masculine societies in which there is a maximum emotional and role differentiation between genders, men are thought to be assertive and ambitious, women more caring, work prevails over family and there is admiration for the strong. Conversely, feminine societies are characterized by a minimum emotional and social role differentiation between genders, where men and women should be modest and caring, a balance between family and work is sought, and there is sympathy for the weak. Consequently, masculine cultures tend to be more assertive, competitive and strong, where roles of achievement, control and power are reinforced (Hofstede, 2001). 
In terms of masculinity vs femininity and the preferences for CMSs, Oudenhoven et al. (1998), and Gabrielidis et al. (1997), showed that individuals from more feminine cultures tend to prefer problem solving. We argue that individuals expressing high values of masculinity values will tend to prefer assertive and competitive styles of managing conflict and negotiations (i.e. forcing and competitive negotiation). We expect individuals with masculine values also to show less preference for those unassertive styles, such as avoiding, as well as prefer competition over compromise and cooperation, which could be labelled as weaknesses within masculine cultures (Brewer, Mitchell, \& Weber, 2002). Conversely, individuals with lower adherence to masculine values are expected to prefer those styles that tend to avoid engagement in the conflict (i.e. avoiding) or include a concern for the other party (i.e. yielding, problem solving and compromising).

H4a: Individuals high in masculinity are negatively related to the avoiding style.

H4b: Individuals high in masculinity are positively related to the forcing style.

H4c: Individuals high in masculinity are negatively related to the problem-solving style.

Long-term orientation, as opposed to short term, relates to the choice of focus (future, present and past) for people's efforts (Hofstede, 2011). Individuals with long-term orientations cultural function under the belief that the most important events in life will occur in the future, therefore people, traditions and ethical values should adapt to circumstances, and hard work, thrift and perseverance are important goals (Hofstede, 2001). In the context of individual preferences for CMSs, we argue that individuals expressing high values of long-term orientations are expected to engage in CMSs where concern for the other is higher. Individuals with long-term orientation reflect on the self and expectation of outcomes in the future and therefore, we expect that their choice would fall on the problem solving style, which is usually considered effective for maintaining long-term relationships and achieving long-term goals (Pruitt \& Rubin, 1986). To the best of our knowledge only Gunkel et al. (2016) have investigated the relationship between long-term orientation and CMSs, reporting that long-term orientation was positively related to problem solving. We also expect that long-term orientation will also tend to decrease the preference for 
non-engaging CMSs such as avoiding. Moreover, as short-term oriented cultures prefer short-term gain, we expect that forcing style will tend to be preferred by such individuals, as they might give the perception of a higher immediate gain. Such logic is consistent also with the view that if conflict is not properly managed, there is a high chance that the negatives will outweigh the positives, consequently individuals with long-term orientation will tend to engage in actively manage the conflict in a way that avoid future negatives, acknowledging and respecting the interest of the other party.

H5a: Individuals high in long-term orientation are negatively related to the avoiding style.

H5b: Individuals high in long-term orientation are negatively related to the forcing style.

H5c: Individuals high in long-term orientation are positively related to the problem-solving style.

We know that intelligence, such as emotional intelligence, plays a role in mediating the relationships between cultural orientations and CMSs (Gunkel et al., 2016). However, the level of interpersonal skills that employees possess within a culture is independent from the level of interpersonal skills that those employees possess across cultures (Earley \& Ang, 2003; Groves \& Feyerherm, 2011). The fact that an individual has a high level of interpersonal skills in his or her own culture does not necessarily mean that he/she may be able to adapt to other people when exposed to a new culture. Therefore, we believe the study of CQ is needed when investigating conditional indirect effects between cultural values and CMSs. Although the need to explore the link between conflict, conflict management style and CQ has been raised (Aycan \& Gelfand, 2012), yet empirical studies on the subject are limited.

In the context of CMSs, Chen, Wu and Bian (2014) found that what they called active and agreeable CMS moderated the relationship between CQ and cross-cultural adjustment of international students in Taiwan. Specifically, active CMS negatively moderated the relationship, while agreeable CMS positively moderated the relationship. Gonçalves et al. (2016) investigated the extent to which CQ and self-monitoring can positively influence the ability to solve interpersonal conflicts more effectively, finding the four facets of CQ predicting the problem-solving style. The research connecting CQ robustly to CMSs are limited and not always comparable due to sample and measurements diversity. We are aware 
that from prior research on CMSs (e.g., De Dreu et al., 2001; Euwema, Vliert, \& Bakker, 2003) that the choice of CMSs stems from some characteristics of the individual making the choice. For example, an individual who ignores what others want will tend to use a competing than other conflict management styles. Conversely, an individual who self-sacrifices for the common good of others and strives to maintain relationships will tend to use more collaborative oriented CMSs. Additionally, an individual who lacks interest in self, others, or even in the issue at stake will most likely withdraw from the situation, resulting in avoiding the conflict. We argue that the above individual characteristics (competing, collaborative and avoidance) are also driven by their different cultural orientations. In this regard, Holt and DeVore (2005) show that past experiences and cultural orientations can affect one's understanding of conflict and conflict management. Given the above, we argue that CQ would moderate the impact of cultural values/orientations on conflict management styles. This is because a culturally intelligent individual would most likely adapt his/her behavior to function appropriately in the different culture, mitigating the challenges of conflict and conflict management in culturally diverse contexts.

H6a: CQ will negatively moderate the relationships between cultural orientations and the avoiding style. H6b: CQ will positively moderate the relationships between cultural orientations and the forcing style. H6c: CQ will positively moderate the relationships between cultural orientations and the problem solving style. 
Figure 2 - Hypothesized interactions

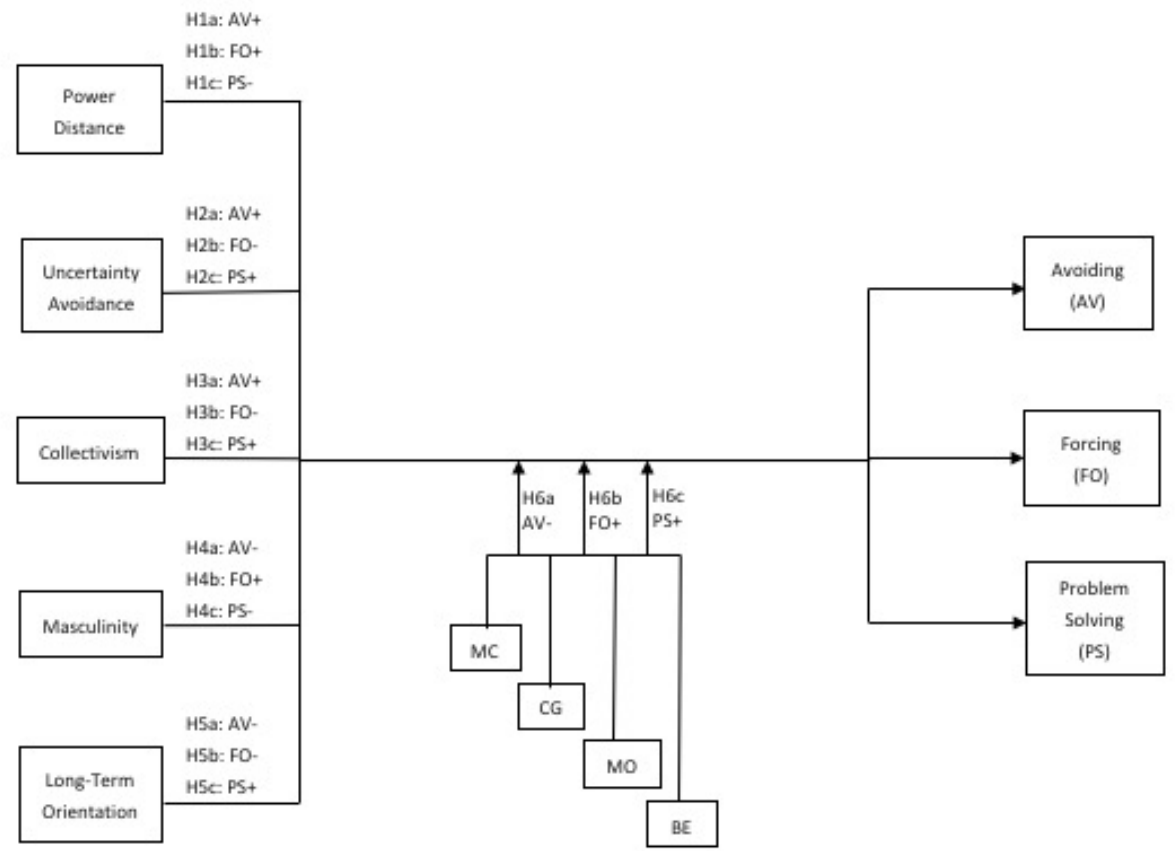

Note: Hypotheses 1 to 5 are related to the direct relationships of the five Cultural Values and Orientations (CVO) to the three Conflict Management Styles (CMS). For example, H1a: AV+ is the notation to mean that it is proposed that Power Distance will be positively related to Avoiding. Hypotheses 6a-c are the moderating effects of the four Cultural Intelligence (CQ) variables - Metacognitive (MC); Cognitive (CG); Motivational (MO); and Behavioral (BE) on the direct relationships between the CVO variables and the CMS variables. For example H6a: $\mathrm{AV}$-, proposes the four CQ variables will negatively moderates the relationship between each $\mathrm{CVO}$ and Avoiding style.

\section{Methodology}

\subsection{Sample and procedures}

Questionnaires were distributed online using a panel service that allow researchers to compensate participants for their time in participating the study (www.prolific.ac.uk), allowing us to select participants from a pool of currently employed non-student individuals. Similar to previous studies in cultural differences and conflict management, we adopted self-reported measures (e.g., Caputo, 2016; Gunkel et al., 2016). One Instrumental Manipulation Check (IMC) question was included in the survey to instruct participants to demonstrate that they are paying attention by performing a non-sensical task (Berinsky, Margolis, \& Sances, 2014). A total number of 450 questionnaires were retrieved, of those 47 
were discarded because they were either incomplete or failed the IMC. A total of 403 questionnaires were employed for data analysis. Table 1 provides descriptive statistics on the demographics of our sample.

The average age was 34.4 years (S.D. $=9.6)$, ranging from 19 to 68 years old.

Demographic variables were not included in our analyses, and t-test analyses showed that there was no significant difference between the groups in our demographic variables. To minimize the risk of biases in self-reported surveys, we checked for robustness (Podsakoff, MacKenzie, Lee, \& Podsakoff, 2003). In all tests, we did not find any statistically significant difference $(p>0.05)$. We also checked for common method variance using the Harman one-factor method which showed that the first factor accounted for only $11 \%$ of the total variance, suggesting no serious common method problem (Gunkel et al., 2016; Podsakoff \& Organ, 1986).

Table 1 - Demographic characteristics $(n=403)$

\begin{tabular}{|c|c|c|c|c|c|c|c|c|c|c|c|}
\hline \multicolumn{2}{|c|}{ Gender } & \multicolumn{2}{|c|}{ Nationality } & \multicolumn{2}{|c|}{ Ethnicity } & \multicolumn{2}{|c|}{ Religion } & \multicolumn{2}{|c|}{ Multicultural experience } & \multicolumn{2}{|c|}{ Multinational experience } \\
\hline Female & $54 \%$ & $\overline{\mathrm{UK}}$ & $40 \%$ & White & $63 \%$ & Religious & $53 \%$ & $\overline{\text { Yes }}$ & $76 \%$ & Yes & $59 \%$ \\
\hline Male & $46 \%$ & Other & $60 \%$ & Other & $37 \%$ & Non-religious & $47 \%$ & No & $24 \%$ & No & $41 \%$ \\
\hline
\end{tabular}

\subsection{Measures}

Cultural orientations were measured with the CVSCALE (Yoo et al., 2011), a 26 item of individual cultural values that assesses Hofstede's cultural dimensions on a 5-point Likert scale. There are five sub-constructs in this scale: Collectivism; Long-Term Orientation; Masculinity; Power Distance; and Uncertainty Avoidance. Cultural intelligence was measured as a second order factor through the Cultural Intelligence Scale (CQS, Ang et al., 2007), a widely used 20-item scale (e.g., Vlajčić et al., 2018) that measures, on a 5-point Likert scale, four first order factors: Cognitive; Metacognitive; Motivational; and Behavioral. The CMSs of avoiding, forcing and problem solving, were measured using the 20 -item DUTCH scale for conflict handling (De Dreu et al., 2001). All measurements were done using 5-point Likert scale ranging from $1=$ "Strongly disagree" to $5=$ "Strongly agree". Consistently with recent 
research on CQ (Vlajčić et al., 2018), demographics (Age and Working Experience) were considered as control variables.

Table 2 - Measures

\begin{tabular}{cccccc}
\hline Construct & Scale & No. of Items & Cronbach's Alpha ( $\boldsymbol{\alpha})$ & AVE & CR \\
\hline Collectivism & CVSCALE (Yoo et al., 2011) & 6 & .83 & .46 & .81 \\
Long-Term Orientation & CVSCALE (Yoo et al., 2011) & 6 & .72 & .30 & .67 \\
Masculinity & CVSCALE (Yoo et al., 2011) & 4 & .79 & .49 & .79 \\
Power Distance & CVSCALE (Yoo et al., 2011) & 5 & .77 & .40 & .77 \\
Uncertainty Avoidance & CVSCALE (Yoo et al., 2011) & 5 & .75 & .39 & .76 \\
Cognitive CQ & CQS (Ang et al., 2007) & 6 & .89 & .57 & .89 \\
Metacognitive CQ & CQS (Ang et al., 2007) & 4 & .86 & .61 & .86 \\
Motivational CQ & CQS (Ang et al., 2007) & 5 & .85 & .57 & .87 \\
Behavioural CQ & CQS (Ang et al., 2007) & 5 & .86 & .57 & .86 \\
Avoiding & DUTCH (De Dreu et al., 2001) & 4 & .73 & .56 & .79 \\
Problem Solving & DUTCH (De Dreu et al., 2001) & 4 & .69 & .33 & .66 \\
Forcing & DUTCH (De Dreu et al., 2001) & 4 & .74 & .41 & .73 \\
\hline
\end{tabular}

\section{Analysis and Results}

\subsection{Measurement Model and Confirmatory Factor Analysis (CFA)}

We used Structural Equation Modelling (AMOS in SPSS) to examine all the various constructs in our study. The maximum likelihood method was used to undertake a confirmatory factor analysis (CFA) for each of the main three constructs - Cultural Orientations; Cultural Intelligence; and Conflict Management Styles. We used several fit indices to evaluate the goodness of fit of these main constructs as provided in Table 3.

Table 3 - Fit indices

\begin{tabular}{cccccccc}
\hline Construct & $\boldsymbol{X}^{\mathbf{2}}$ & $\mathbf{d f}$ & $\boldsymbol{X}^{\mathbf{2}} / \mathbf{d f}$ & $\boldsymbol{p}$ & $\mathbf{C F I}$ & RMSEA & SRMR \\
\hline Cultural Orientation & 448.48 & 199 & 2.254 & .000 & .91 & .06 & .063 \\
Cultural Intelligence & 388.67 & 166 & 2.341 & .000 & .95 & .06 & .052 \\
Conflict Management Styles & 108.072 & 34 & 3.179 & .000 & .94 & .07 & .061 \\
\hline
\end{tabular}


We improved the fit by removing items that were not helping the model and final revised model for each construct had at least 3 items for each of its sub-construct. All fit indices resulted in acceptable values for the model (e.g., Hu \& Bentler, 1999; Wheaton, Muthen, Alwin, \& Summers, 1977). CQ was conceptualized and tested as a second-order factor and as Table 3 indicates, it fit indices $(\mathrm{CFI}=0.95$; RMSEA $=0.058 ;$ CMIN/DF $=2.341)$ were good (e.g., Byrne, 2001). Table 4 provides the descriptive statistics and bivariate correlation of all the key variables in the study. We assessed multicollinearity with bivariate correlations and did not report any issue following Hair and colleagues (2012) procedure. 
Table 4 - Correlation matrix and descriptive statistics $(n=403)$

\begin{tabular}{|c|c|c|c|c|c|c|c|c|c|c|c|c|c|c|c|}
\hline & & 1 & 2 & 3 & 4 & 5 & 6 & 7 & 8 & 9 & 10 & 11 & 12 & 13 & 14 \\
\hline 1 & Avoiding & & & & & & & & & & & & & & \\
\hline 2 & Problem Solving & .094 & & & & & & & & & & & & & \\
\hline 3 & Forcing & -.007 & $.281^{* *}$ & & & & & & & & & & & & \\
\hline 4 & Power Distance & $.223^{* *}$ & -.009 & $.268^{* *}$ & & & & & & & & & & & \\
\hline 5 & Uncertainty Avoidance & $.189^{* *}$ & $.374^{* * *}$ & $.212^{* *}$ & .017 & & & & & & & & & & \\
\hline 6 & Collectivism & $.152^{* *}$ & $.291^{* *}$ & $.120^{*}$ & $.267^{* *}$ & $.170^{* *}$ & & & & & & & & & \\
\hline 7 & Long-Term Orientation & $.142^{* *}$ & $.487^{* *}$ & $.254^{* *}$ & -0.013 & $.513^{* *}$ & $.331^{* * *}$ & & & & & & & & \\
\hline 8 & Masculinity & $.124^{*}$ & -.062 & $.244^{* *}$ & $.523^{* *}$ & $.125^{*}$ & $.223^{* *}$ & .049 & & & & & & & \\
\hline 9 & Metacognitive CQ & -.081 & $.436^{* *}$ & $.207^{* *}$ & -.075 & $.277^{* *}$ & $.171^{* *}$ & $.281^{* *}$ & -.046 & & & & & & \\
\hline 10 & Cognitive CQ & $-.099^{*}$ & $.236^{* *}$ & $.279^{* *}$ & $.214^{* *}$ & .055 & $.199^{* *}$ & $.140^{* *}$ & $.201^{* *}$ & $.493^{* *}$ & & & & & \\
\hline 11 & Motivational CQ & $-.157^{* *}$ & $.312^{* *}$ & $.113^{*}$ & $-.114^{*}$ & .093 & $.137^{* *}$ & $.164^{* *}$ & $-.111^{*}$ & $.520^{* *}$ & $.520^{* *}$ & & & & \\
\hline 12 & Behavioural CQ & .009 & $.287^{* *}$ & $.109^{*}$ & .003 & $.141^{* *}$ & $.150^{* *}$ & $.174^{* *}$ & .002 & $.616^{* *}$ & $.477^{* *}$ & $.468^{* *}$ & & & \\
\hline 13 & Age & .057 & $-.138^{* *}$ & $-.178^{* *}$ & -.015 & $-.119^{*}$ & -.069 & -.082 & -.069 & $-.100^{*}$ & $-.208^{* *}$ & -.033 & $-.112^{*}$ & & \\
\hline 14 & Working experience & .042 & $-.132^{* *}$ & $-.133^{* *}$ & -.070 & $-.140^{* *}$ & $-.101^{*}$ & -.082 & $-.126^{*}$ & -.085 & $-.215^{* *}$ & -.032 & -.090 & $.884^{* *}$ & \\
\hline & Mean & 3.31 & 3.92 & 3.19 & 1.97 & 4.09 & 3.23 & 4.20 & 2.21 & 3.81 & 2.88 & 3.74 & 3.44 & 34.44 & 12.48 \\
\hline & S.D. & .94 & .58 & .76 & .73 & .57 & .71 & .62 & .96 & .79 & .89 & .81 & .86 & 9.60 & 9.58 \\
\hline
\end{tabular}

* Correlation is significant at the .05 level (2-tailed)

** Correlation is significant at the .01 level (2-tailed). 


\subsection{Model Specification and Hypothesis Testing}

To test our hypotheses, we conceptualized three separate models based on our main dependent variables, i.e. avoiding (AVOID), forcing (FORCE) and problem solving (PROBSOLV).

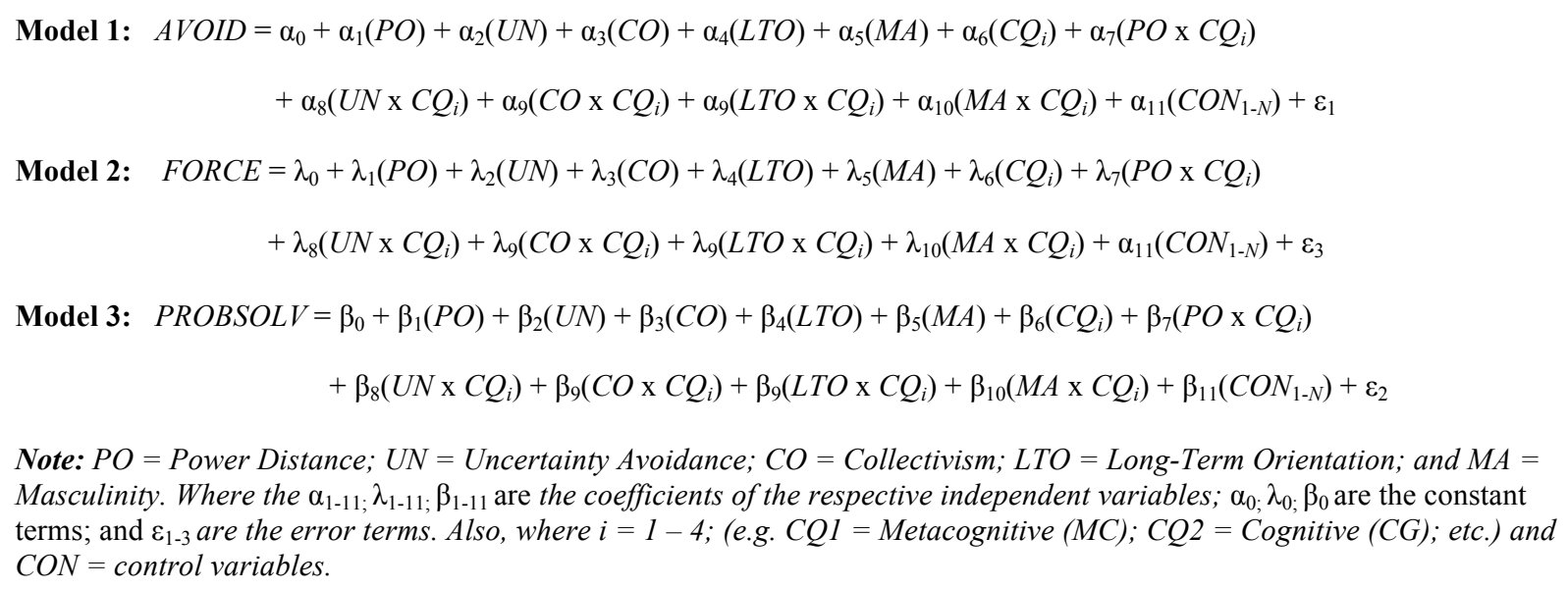

Note: $P O=$ Power Distance; $U N=$ Uncertainty Avoidance; $C O=$ Collectivism; $L T O=$ Long-Term Orientation; and $M A=$ Masculinity. Where the $\alpha_{1-11 ;} \lambda_{1-11 ;} \beta_{1-11}$ are the coefficients of the respective independent variables; $\alpha_{0} ; \lambda_{0} ; \beta_{0}$ are the constant terms; and $\varepsilon_{1-3}$ are the error terms. Also, where $i=1-4$; (e.g. CQ1 = Metacognitive $(M C) ; C Q 2=$ Cognitive $(C G) ;$ etc.) and $C O N=$ control variables.

Regarding the four Cultural Intelligence facets (CQ) interacting the three main models, we tested for $3 \times 4$ regression equations and the comprehensive results are shown in Table 5. In the tables we report the standardized coefficients. We used Moderated Multiple Regression Analysis (MMRA) for testing all the twelve (12) equations. As recommended variables were mean-centered (e.g., Aiken, West, \& Reno, 1991; Dawson, 2014). The variances inflation factors (VIF) and tolerance the for all the regression equations indicated that both were within acceptable levels, $\mathrm{VIF}<5$; and tolerance $>0.2$ (Bowerman \& O'connell, 1990; Menard, 1995). We entered the variables in the regression analysis in a hierarchical order as follows: control variables; then the five cultural orientation dimensions; then enter the moderator variable; finally, the interacting terms as a product term of the moderator with each of the five cultural orientations. 
Table 5 - Results of moderated multiple regression analysis

\begin{tabular}{|c|c|c|c|c|c|c|c|c|c|c|c|c|}
\hline \multirow{2}{*}{ Variables } & \multicolumn{4}{|c|}{ Avoiding as Dependent Variable } & \multicolumn{4}{|c|}{ Problem Solving as Dependent Variable } & \multicolumn{4}{|c|}{$\underline{\text { Forcing as Dependent Variable }}$} \\
\hline & $\underline{\mathrm{MC}}$ & $\underline{\mathbf{C G}}$ & $\underline{\text { MO }}$ & $\underline{\mathbf{B E}}$ & $\underline{\mathbf{M C}}$ & $\underline{\mathbf{C G}}$ & $\underline{\text { MO }}$ & $\underline{\mathbf{B E}}$ & $\underline{\mathbf{M C}}$ & $\underline{\mathbf{C G}}$ & $\underline{\text { MO }}$ & $\underline{\mathbf{B E}}$ \\
\hline \multicolumn{13}{|l|}{ Direct Effects } \\
\hline Age & .02 & .02 & .02 & .01 & -.09 & -.06 & -.14 & -.09 & $-.33 * *$ & $-.31 * * *$ & $-.33 * * *$ & $-.31 * *$ \\
\hline Working experience & .07 & .05 & .07 & .10 & .03 & .00 & .06 & .03 & $.24^{*}$ & $.24 *$ & $.22 *$ & $.20^{*}$ \\
\hline Power Distance & $.20 * * *$ & $.22 * * *$ & $.17 * *$ & $.20 * * *$ & .03 & -.02 & .03 & .00 & $.23 * * *$ & $.16^{* *}$ & $.22 * * *$ & $.22 * * *$ \\
\hline Uncertainty Avoidance & $.20 * * *$ & $.16^{* *}$ & $.18 * * *$ & $.15^{* *}$ & $.14 * *$ & $.20 * * *$ & $.18 * * *$ & $.16^{* * *}$ & .04 & $.11 *$ & .08 & .09 \\
\hline Collectivism & .07 & .07 & .07 & .07 & $.14 * *$ & $.14^{* *}$ & $.12^{* *}$ & $.16^{* * *}$ & -.07 & -.08 & -.08 & -.06 \\
\hline Long-Term Orientation & .09 & .07 & .08 & .07 & $.29 * * *$ & $.30 * * *$ & $.32 * * *$ & $.32 * * *$ & $.19 * * *$ & $.17 * *$ & $.20 * * *$ & $.19 * * *$ \\
\hline Masculinity & -.04 & -.01 & -.04 & -.03 & $-.14 * *$ & $-.17 * * *$ & $-.13 * *$ & $-.16^{* * *}$ & $.13^{*}$ & .09 & $.14^{* *}$ & $.11 *$ \\
\hline \multicolumn{13}{|l|}{ Interaction Effects } \\
\hline Moderator & $-.14 * *$ & $-.18^{* * *}$ & $-.17 * * *$ & -.05 & $.29 * * *$ & $.15^{* * *}$ & $.21 * * *$ & $.17 * * *$ & $.16^{* * *}$ & $.18 * * *$ & $.12 * *$ & .06 \\
\hline x Power Distance & -.02 & .03 & .01 & .00 & $.10^{*}$ & .07 & .00 & .08 & $.16^{* *}$ & $.23 * * *$ & $.14^{*}$ & $.16^{* *}$ \\
\hline x Uncertainty Avoidance & .05 & .03 & .02 & .03 & -.03 & .07 & -.07 & -.04 & $.12 *$ & $.11 *$ & $.18^{* *}$ & .07 \\
\hline x Collectivism & .05 & .02 & .03 & .08 & -.01 & -.06 & -.04 & -.07 & -.01 & .00 & -.05 & -.02 \\
\hline x Long-Term Orientation & .08 & -.01 & $.15^{*}$ & .11 & $.16^{* *}$ & -.03 & $.16^{* *}$ & $.16^{* *}$ & -.07 & -.11 & -.03 & -.05 \\
\hline x Masculinity & .04 & .05 & .06 & .03 & .03 & .04 & $.16^{* *}$ & .06 & -.05 & $-.13^{*}$ & -.04 & -.09 \\
\hline \multicolumn{13}{|l|}{$\underline{R^{2} \text { Changes }}\left(\Delta R^{2}\right)$} \\
\hline Control Variables & .00 & .00 & .00 & .00 & .02 & .02 & .02 & .02 & .03 & .03 & .03 & .03 \\
\hline 5 Cultural Orientations & .09 & .09 & .09 & .09 & .28 & .28 & .28 & .28 & .15 & .15 & .15 & .15 \\
\hline Moderator & .02 & .03 & .03 & .00 & .07 & .03 & .04 & .03 & .02 & .03 & .01 & .00 \\
\hline Interacting Terms & .02 & .01 & .03 & .03 & .03 & .01 & .03 & .02 & .02 & .04 & .03 & .02 \\
\hline Full model & .14 & .13 & .15 & .13 & .40 & .34 & .37 & .36 & .23 & .26 & .23 & .21 \\
\hline \multicolumn{13}{|l|}{ 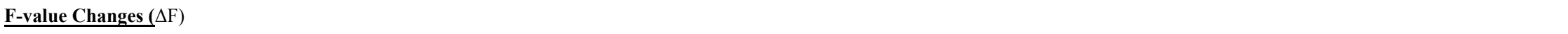 } \\
\hline Control Variables & .74 & .74 & .74 & .74 & $3.98^{*}$ & $3.98^{*}$ & $3.98^{*}$ & $3.98^{*}$ & $7.09 * * *$ & $7.09 * * *$ & $7.09 * * *$ & $7.09^{* * *}$ \\
\hline 5 Cultural Orientations & $8.28 * *$ & $8.28^{* * *}$ & $8.28 * * *$ & $8.28 * * *$ & $32.18 * * *$ & $32.18^{* * *}$ & $32.18^{* * *}$ & $32.18 * * *$ & $14.94 * * *$ & $14.94 * * *$ & $14.94 * * *$ & $14.94 * * *$ \\
\hline Moderator & $8.20 * *$ & $11.56^{* *}$ & $12.78^{* *}$ & .25 & $44.44 * * *$ & $15.54 * * *$ & $25.55^{* * *}$ & $17.65^{* * *}$ & $11.29 * * *$ & $14.46^{* * *}$ & $6.66^{* *}$ & 1.25 \\
\hline Interacting Term & 2.14 & .61 & $2.58^{*}$ & $2.80^{*}$ & $3.37 * *$ & 1.34 & $3.58^{* *}$ & $2.98^{*}$ & $2.48^{*}$ & $4.08 * * *$ & $3.30 * *$ & $2.37 *$ \\
\hline
\end{tabular}

$* \mathrm{p}<.05 ; * * \mathrm{p}<.01 ; * * * \mathrm{p}<.001 \mathrm{MC}=$ Metacognitive; $\mathrm{CG}=$ Cognitive; $\mathrm{MO}=$ Motivational; $\mathrm{BE}=$ 3ehavioral 
The two control variables (age and working experience) contribute to only $2 \%$ of the variance explained to model $3(\Delta \mathrm{F}=3.98, \mathrm{p}<0.05), 3 \%$ to model $2(\Delta \mathrm{F}=7.09, \mathrm{p}<0.001)$, and do not contribute any variance explained to model $1\left(\Delta \mathrm{F}=0.74, \mathrm{p}=\right.$ n.s. $\left.{ }^{1}\right)$. The five cultural orientations all contribute to the three models. The greatest of these is contributed with problem solving $\left(\Delta \mathrm{R}^{2}=28 \%, \Delta \mathrm{F}=32.18, p<\right.$ $0.001)$, followed by forcing $\left(\Delta \mathrm{R}^{2}=15 \%, \Delta \mathrm{F}=14.94, p<0.001\right)$ and the smallest being with avoiding $\left(\Delta \mathrm{R}^{2}=9 \%, \Delta \mathrm{F}=8.28, \mathrm{p}<0.001\right)$. The four cultural intelligence facets had a significant negative direct effect with avoiding apart from when behavioral CQ was moderating $(\alpha=-.05, p=\mathrm{n} . \mathrm{s} . ; \Delta \mathrm{F}=0.25, p=$ n.s.). They also had a positive significant effect on both problem solving and forcing, but for forcing the effect was non-significant when Behavioral was moderating $(\alpha=.06, p=$ n.s.; $\Delta \mathrm{F}=1.25, p=$ n.s. $)$. Altogether, each of the CQ facets explains only small (up to 7\%) or no variance.

Table 6 and 7 show an extract and a summary of the comprehensive test results shown Table 5 and in these tables, we additionally report the $t$-values of the respective coefficients.

\footnotetext{
${ }^{1}$ N.s. meaning the value was not significant.
} 
Table 6 - Summary of tests for hypotheses 1 to 5.

\begin{tabular}{|c|c|c|c|c|c|c|c|c|}
\hline & \multirow[t]{2}{*}{$\begin{array}{l}\text { Independent } \\
\text { Variable }\end{array}$} & & \multirow[t]{2}{*}{$\begin{array}{l}\text { Dependent } \\
\text { Variable }\end{array}$} & \multirow[t]{2}{*}{ Test Results } & \multicolumn{4}{|c|}{$\begin{array}{c}\text { Standardized Coefficients } \\
\text { (t-value) }\end{array}$} \\
\hline & & & & & Metacognitive & Cognitive & Motivational & Behavioral \\
\hline $\mathrm{H} 1 \mathrm{a}(+)$ & Power Distance & $\rightarrow$ & Avoiding & Supported & $\begin{array}{l}.20^{* * *} \\
(3.410)\end{array}$ & $\begin{array}{l}.22 * * * \\
(3.666)\end{array}$ & $\begin{array}{l}.17 * * * \\
(2.980)\end{array}$ & $\begin{array}{l}.20^{* * *} \\
(3.531)\end{array}$ \\
\hline $\mathrm{H} 1 \mathrm{~b}(+)$ & Power Distance & $\rightarrow$ & Forcing & Supported & $\begin{array}{l}.23 * * * \\
(4.237)\end{array}$ & $\begin{array}{c}.16^{* *} \\
(2.934)\end{array}$ & $\begin{array}{l}.22 * * * \\
(3.999)\end{array}$ & $\begin{array}{l}.22 * * * \\
(4.048)\end{array}$ \\
\hline $\mathrm{H} 1 \mathrm{c}(-)$ & Power Distance & $\rightarrow$ & $\begin{array}{l}\text { Problem } \\
\text { Solving }\end{array}$ & Not Supported & $\begin{array}{c}.03 \\
(.604)\end{array}$ & $\begin{array}{c}-.02 \\
(-.307)\end{array}$ & $\begin{array}{c}.03 \\
(.588)\end{array}$ & $\begin{array}{c}.00 \\
(.059)\end{array}$ \\
\hline $\mathrm{H} 2 \mathrm{a}(+)$ & $\begin{array}{l}\text { Uncertainty } \\
\text { Avoidance }\end{array}$ & $\rightarrow$ & Avoiding & Supported & $\begin{array}{l}.20 * * * \\
(3.573)\end{array}$ & $\begin{array}{c}.16^{* *} \\
(2.785)\end{array}$ & $\begin{array}{l}.18^{* * *} \\
(3.203)\end{array}$ & $\begin{array}{c}.15^{* *} \\
(2.649)\end{array}$ \\
\hline $\mathrm{H} 2 \mathrm{~b}(-)$ & $\begin{array}{l}\text { Uncertainty } \\
\text { Avoidance }\end{array}$ & $\rightarrow$ & Forcing & Not Supported & $\begin{array}{c}.04 \\
(.806)\end{array}$ & $\begin{array}{c}.11 \\
(2.042)\end{array}$ & $\begin{array}{c}.08 \\
(1.498)\end{array}$ & $\begin{array}{c}.09 \\
(1.638)\end{array}$ \\
\hline $\mathrm{H} 2 \mathrm{c}(+)$ & $\begin{array}{l}\text { Uncertainty } \\
\text { Avoidance }\end{array}$ & $\rightarrow$ & $\begin{array}{l}\text { Problem } \\
\text { Solving }\end{array}$ & Supported & $\begin{array}{c}.14^{* *} \\
(2.914)\end{array}$ & $\begin{array}{l}.20 * * * \\
(4.122)\end{array}$ & $\begin{array}{l}.18 * * * \\
(3.781)\end{array}$ & $\begin{array}{l}.16^{* * *} \\
(3.216)\end{array}$ \\
\hline $\mathrm{H} 3 \mathrm{a}(+)$ & Collectivism & $\rightarrow$ & Avoiding & Not Supported & $\begin{array}{c}.07 \\
(1.242)\end{array}$ & $\begin{array}{c}.07 \\
(1.256)\end{array}$ & $\begin{array}{c}.07 \\
(1.313)\end{array}$ & $\begin{array}{c}.07 \\
(1.329)\end{array}$ \\
\hline $\mathrm{H} 3 \mathrm{~b}(-)$ & Collectivism & $\rightarrow$ & Forcing & Not Supported & $\begin{array}{c}-.07 \\
(-1.425)\end{array}$ & $\begin{array}{c}-.08 \\
(-1.624)\end{array}$ & $\begin{array}{c}-.08 \\
(-1.609)\end{array}$ & $\begin{array}{c}-.06 \\
(-1.211)\end{array}$ \\
\hline $\mathrm{H} 3 \mathrm{c}(+)$ & Collectivism & $\rightarrow$ & $\begin{array}{l}\text { Problem } \\
\text { Solving }\end{array}$ & Supported & $\begin{array}{c}.14 * * \\
(3.057)\end{array}$ & $\begin{array}{c}.14^{* *} \\
(3.016)\end{array}$ & $\begin{array}{c}.12 * * \\
(2.601)\end{array}$ & $\begin{array}{l}.16^{* * *} \\
(3.531)\end{array}$ \\
\hline $\mathrm{H} 4 \mathrm{a}(-)$ & Masculinity & $\rightarrow$ & Avoiding & Not Supported & $\begin{array}{c}-.04 \\
(-.651)\end{array}$ & $\begin{array}{c}-.01 \\
(-.095)\end{array}$ & $\begin{array}{c}-.04 \\
(-.666)\end{array}$ & $\begin{array}{c}-.03 \\
(-.448)\end{array}$ \\
\hline $\mathrm{H} 4 \mathrm{~b}(+)$ & Masculinity & $\rightarrow$ & Forcing & Supported & $\begin{array}{c}.13 * * \\
(2.488)\end{array}$ & $\begin{array}{c}.09^{*} \\
(1.779)\end{array}$ & $\begin{array}{c}.14^{* *} \\
(2.575)\end{array}$ & $\begin{array}{c}.11^{* *} \\
(2.125)\end{array}$ \\
\hline $\mathrm{H} 4 \mathrm{c}(-)$ & Masculinity & $\rightarrow$ & $\begin{array}{l}\text { Problem } \\
\text { Solving }\end{array}$ & Supported & $\begin{array}{c}-.14 * * \\
(-3.073)\end{array}$ & $\begin{array}{l}-.17 * * * \\
(-3.372)\end{array}$ & $\begin{array}{c}-.13 * * \\
(-2.689)\end{array}$ & $\begin{array}{l}-.16^{* * *} \\
(-3.202)\end{array}$ \\
\hline H5a(-) & $\begin{array}{l}\text { Long-Term } \\
\text { Orientation }\end{array}$ & $\rightarrow$ & Avoiding & Not Supported & $\begin{array}{c}.09 \\
(1.514)\end{array}$ & $\begin{array}{c}.07 \\
(1.196)\end{array}$ & $\begin{array}{c}.08 \\
(1.388)\end{array}$ & $\begin{array}{c}.07 \\
(1.144)\end{array}$ \\
\hline $\mathrm{H} 5 \mathrm{~b}(-)$ & $\begin{array}{l}\text { Long-Term } \\
\text { Orientation }\end{array}$ & $\rightarrow$ & Forcing & Not Supported & $\begin{array}{l}.19^{* * *} \\
(3.463)\end{array}$ & $\begin{array}{c}.17^{* *} \\
(3.181)\end{array}$ & $\begin{array}{l}.20^{* * *} \\
(3.709)\end{array}$ & $\begin{array}{l}.19^{* * *} \\
(3.445)\end{array}$ \\
\hline $\mathrm{H} 5 \mathrm{c}(+)$ & $\begin{array}{l}\text { Long-Term } \\
\text { Orientation }\end{array}$ & $\rightarrow$ & $\begin{array}{l}\text { Problem } \\
\text { Solving }\end{array}$ & Supported & $\begin{array}{l}.29 * * * \\
(5.908)\end{array}$ & $\begin{array}{l}.30^{* * * *} \\
(5.919)\end{array}$ & $\begin{array}{l}.32 * * * \\
(6.406)\end{array}$ & $\begin{array}{l}.32 * * * \\
(6.314)\end{array}$ \\
\hline
\end{tabular}

$t$-values are in parenthesis below the respective standardised coefficient

Hypothesis 1 predicts that Power Distance is positively related to Avoiding (H1a) and Forcing (H1b); and for H1c will be negatively related to Problem Solving style of conflict management. The results show that $\mathrm{H} 1 \mathrm{a}$ and $\mathrm{H} 1 \mathrm{~b}$ are supported; but $\mathrm{H} 1 \mathrm{c}$ is not supported. Hypothesis 2 predicts that Uncertainty Avoidance is positively related to Avoiding (H2a) and Problem Solving (H2c); and negatively related to Forcing $(\mathrm{H} 2 \mathrm{~b})$. The results show that $\mathrm{H} 2 \mathrm{a}$ and $\mathrm{H} 2 \mathrm{c}$ are supported, while $\mathrm{H} 2 \mathrm{~b}$ is not 
supported. Hypothesis 3 predicts that Collectivism is positively related to Avoiding (H3a) and Problem Solving (H3c) but will be negatively related to Forcing (H3b). The results show that H3c is supported; while $\mathrm{H} 3 \mathrm{a}$ and $\mathrm{H} 3 \mathrm{~b}$ are not supported. Hypothesis 4 predicts that Masculinity is negatively related to Avoiding (H4a) and Problem Solving (H4c) but will be positively related to Forcing (H4b). The result show that $\mathrm{H} 4 \mathrm{~b}$ and $\mathrm{H} 4 \mathrm{c}$ are supported and $\mathrm{H} 4 \mathrm{a}$ is not supported. Hypothesis 5 predicts that Long-term orientation is negatively related to Avoiding (H5a) and Forcing (H5b) but will be positively related Problem Solving (H5c). The results show that Long-term orientation had no relationship with Avoiding and as posited it had a positively significant relationship with problem solving. Long-term orientation had a relationship with forcing, but contrary to the negative relationship we posited, this relationship was rather positive. So $\mathrm{H} 5 \mathrm{c}$ is supported but both $\mathrm{H} 5 \mathrm{a}$ and $\mathrm{H} 5 \mathrm{~b}$ are not supported.

Table 7 - Summary of tests for hypothesis 6.

\begin{tabular}{|c|c|c|c|c|c|c|c|}
\hline \multirow[b]{2}{*}{$\mathrm{H} 6 \mathrm{a}(-)$} & \multirow{2}{*}{$\begin{array}{c}\begin{array}{c}\text { Cultural } \\
\text { orientation }\end{array} \\
\text { Long-Term } \\
\text { Orientation } \\
\end{array}$} & \multirow[b]{2}{*}{$\rightarrow$} & \multirow{2}{*}{$\begin{array}{c}\begin{array}{c}\text { Dependent } \\
\text { Variable }\end{array} \\
\text { Avoiding } \\
\end{array}$} & \multirow{2}{*}{$\begin{array}{c}\begin{array}{c}\text { CQ Moderator } \\
\text { Variable }\end{array} \\
\text { Motivational } \\
\end{array}$} & \multirow{2}{*}{$\begin{array}{c}\text { Test Results } \\
\text { Not supported }\end{array}$} & \multicolumn{2}{|c|}{$\begin{array}{c}\text { Standardized } \\
\text { Coefficients (t-value) }\end{array}$} \\
\hline & & & & & & $.15^{*}$ & $(2.139)$ \\
\hline \multirow{8}{*}{$\mathrm{H} 6 \mathrm{~b}(+)$} & Power Distance & $\rightarrow$ & Forcing & Metacognitive & \multirow{8}{*}{$\begin{array}{l}\text { Supported for } 8 \text { out of the } 20 \\
\text { possible interactions. }\end{array}$} & $.16^{* *}$ & $(2.763)$ \\
\hline & $\begin{array}{l}\text { Uncertainty } \\
\text { Avoidance }\end{array}$ & $\rightarrow$ & Forcing & Metacognitive & & $.12 *$ & (1.971) \\
\hline & Power Distance & $\rightarrow$ & Forcing & Cognitive & & $.23 * * *$ & $(3.752)$ \\
\hline & $\begin{array}{l}\text { Uncertainty } \\
\text { Avoidance }\end{array}$ & $\rightarrow$ & Forcing & Cognitive & & $.11 *$ & (1.992) \\
\hline & Masculinity & $\rightarrow$ & Forcing & Cognitive & & $-.13^{*}$ & $(-2.154)$ \\
\hline & Power Distance & $\rightarrow$ & Forcing & Motivational & & $.14 *$ & $(2.326)$ \\
\hline & $\begin{array}{l}\text { Uncertainty } \\
\text { Avoidance }\end{array}$ & $\rightarrow$ & Forcing & Motivational & & $.18^{* *}$ & (3.076) \\
\hline & Power Distance & $\rightarrow$ & Forcing & Behavioral & & $.16^{* *}$ & $(3.061)$ \\
\hline \multirow{5}{*}{$\mathrm{H} 6 \mathrm{c}(+)$} & Power Distance & $\rightarrow$ & $\begin{array}{l}\text { Problem } \\
\text { Solving }\end{array}$ & Metacognitive & \multirow{5}{*}{$\begin{array}{l}\text { Supported for } 5 \text { out of the } 20 \\
\text { possible interactions. }\end{array}$} & $.10^{*}$ & (1.964) \\
\hline & $\begin{array}{l}\text { Long-Term } \\
\text { Orientation }\end{array}$ & $\rightarrow$ & $\begin{array}{l}\text { Problem } \\
\text { Solving }\end{array}$ & Metacognitive & & $.16^{* *}$ & $(2.621)$ \\
\hline & $\begin{array}{l}\text { Long-Term } \\
\text { Orientation }\end{array}$ & $\rightarrow$ & $\begin{array}{l}\text { Problem } \\
\text { Solving }\end{array}$ & Motivational & & $.16^{* *}$ & $(2.812)$ \\
\hline & Masculinity & $\rightarrow$ & $\begin{array}{l}\text { Problem } \\
\text { Solving }\end{array}$ & Motivational & & $.16^{* *}$ & (3.100) \\
\hline & $\begin{array}{l}\text { Long-Term } \\
\text { Orientation }\end{array}$ & $\rightarrow$ & $\begin{array}{l}\text { Problem } \\
\text { Solving }\end{array}$ & Behavioral & & $.16^{* *}$ & $(2.983)$ \\
\hline
\end{tabular}

Note: Only significant results are reported in the table. ${ }^{*} \mathrm{p}<.05 ; * * \mathrm{p}<.01 ; * * \mathrm{p}<.001$

$t$-values are in parenthesis 
Hypothesis 6a predicted that CQ would negatively moderate the relationships between cultural orientations and the avoiding style. The results show that out of the twenty ( 5 cultural orientations by 4 cultural intelligence facets) possible interactions, there was only one significant interaction effect and this was when the Motivational CQ was positively moderating the relationship between long-term orientation and avoiding $(\alpha=.15, t$-value $=2.458, p<0.05)$ which is contrary to the negative relationship we had posited.

Hypothesis $6 \mathrm{~b}$ predicts that CQ would positively moderate the relationships between cultural orientations and the forcing style. The results show eight interactions out of the twenty possibilities. Metacognitive CQ showed two positive significant moderating effects with power distance and uncertainty avoidance. Cognitive CQ showed two positive significant moderating effects with power distance and uncertainty avoidance; but contrary to our prediction, it had a negative significant moderating effect on masculinity $(\lambda=-.13, t$-value $=-2.153, p<0.05)$. Motivational CQ also had two positive significant moderating effect with power distance and uncertainty avoidance; and Behavioral CQ showed positive significant moderating effect with power distance.

Hypothesis $6 \mathrm{c}$ predicts CQ would positively moderate the relationships between cultural orientations and the problem-solving style. The results showed five significant interactions out of the twenty possible. Metacognitive CQ showed two positive significant moderating effects with power distance and long-term orientation. Motivational CQ also showed two positive significant moderating effects with masculinity and long-term orientation. The other one was Behavioral CQ that showed positive significant moderating effect with long-term orientation. Although Cognitive CQ had a direct effect on problem solving $(\beta=.15, t$-value $=3.361, p<0.001)$, there was no interaction effect when it was moderating any of the five cultural value orientations. 


\section{Discussion}

This study provides supportive evidence about the importance of cultural orientations and cultural intelligence (CQ, metacognitive, cognitive, behavioral, and motivational) for individuals' tendency to choose a certain conflict management style (avoiding, forcing and problem solving).

Our results indicate that power distance is positively related to both avoiding and forcing styles, in harmony with the previous research. For example, studies suggest that power is a basic fact of the society where power distance is practiced and subordinates are expected to do what they are told (e.g., Hofstede, 2011). Our results also show that power distance is also positively related to the avoidance style. This pattern of results is aligned with Kim and colleagues (2007) who found that power distance is also related to avoiding (see also Purohit \& Simmers, 2006). Our results can be explained by the fact that subordinates are most likely to use avoidance conflict management style when involved with their superordinates (with more power) for fear of reprisal (Chandrasiri, 2016). While we had hypothesized that power distance will be negatively related to problem solving, our results show that power distance has no significant relationship with problem solving. Our result is a departure to that of Oudenhoven and colleagues (1998) who found that power distance is positively related to problem solving. Nevertheless, we are aware that individual's behaviors in a power distance culture may depend on whether or not the individual is in power or under power (Kim et al., 2007). There is a possibility that participants in the current study may have been both in power or under power and given our results, these individuals have been more engaged in using more forcing and avoidance styles to managing conflict.

Our research findings show that uncertainty avoidance is positively related to problem solving and avoiding, and this are similar to the results found by Gunkel and colleagues (2016). However, other studies, such as Oudenhoven and colleagues (1998) found that individuals from uncertainty cultural orientation are negatively related to problem solving style. Contrary to our predictions, uncertainty avoidance has no significant relationship with forcing. We know that individuals that are high in uncertainty avoidance are associated with increased stress and anxiety and therefore preoccupied with the need for clarity and structure (Hofstede, 2011). Our results may suggest that their preoccupation with 
clarity and structure may be more important for them than engaging in forcing as conflict management style. More studies are needed to clarify the link between uncertainty avoidance and problem solving style, and perhaps the findings from the studies in cognitive biases, such as risk aversion, may help in clarify this relationship (see also Caputo, 2013).

The results that collectivism is positively related to problem solving confirms the suggestion of Holt and DeVore (2005) that individuals adhering to collectivist cultures tend to prefer problem solving style (see Ting-Toomey et al., 1991). Our result is also in agreement with the findings from Gunkel and colleagues (2016) that collectivism is positively related to problem solving. Furthermore, we had hypothesized that that collectivism will be positively related to avoiding but negatively related to forcing styles. Nevertheless, we found no significant relationship between collectivism and avoidance and forcing, contrary to previous research (Gunkel et al., 2016; Holt \& DeVore, 2005). Our pattern of results may be due to the nature of our sample where majority (63\%) of the participants are Caucasians and not necessarily from the collective cultural orientation.

As hypothesized, we found that masculinity is only related to problem solving but this relationship is negative. This finding is inconsistent with the previous findings in this area. For instance, we are aware from the work of Gabrielidis and colleagues (1997) that individuals with masculinity orientation tend to prefer problem solving conflict management style (see also Oudenhoven et al., 1998). There is a possibility that the participants in our sample are probably more assertive and competitive and therefore less likely to engage in the problem-solving style. Additionally, we found no significant relationship between masculinity, avoiding and forcing. Again, the fact that majority of our participants are Caucasians and are therefore less masculine in their cultural orientation may be a possible reason for this pattern of result.

Long-term orientation is positively related to problem solving as predicted. This result is in harmony with Gunkel and colleagues (2016) who found that individuals with long-term orientation have a preference for problem solving style. This is not surprising as there is also a positive relationship between long-term orientation and emotional intelligence (Gunkel et al., 2016) that might combine to promote 
problem solving for people with long-term orientation. We had expected that long-term orientation would be negatively related to avoidance and forcing styles. Especially because we know that long-term orientation is connected to face saving (Hofstede, 2001) and may thus prefer avoidance to conflict management. However, contrary to predictions, long-term orientation has no significant relationship with avoiding. We also found that long-term orientation has a positive rather than a negative relationship with forcing. The characteristics of our sample may yet again explain the non-significant relationship between long-term orientation and avoidance. Additionally, the positive relationship between long-term orientation and forcing may arise because of the individual with long-term orientation's need for problem solving.

Moving to the role of CQ in the relationship between individual's cultural orientations and their choice of conflict management styles, finding that Motivational CQ positively moderated the link between long-term orientation and avoiding style is exciting. We know that individuals with long-term orientations believe that the most significant events in their lives will be in future and consequently, thrift and perseverance are important goals (Hofstede, 2001) while Motivational CQ demonstrates the capacity to direct energy and drive in cross-cultural adaptations (Earley \& Ang, 2003). Our results suggest that individuals who have long-term orientation but also high in Motivational CQ will most likely choose avoiding style. Our results point to the need to employ avoidance as conflict style as these individuals await their efforts and energy directed to adaption to bear fruit. Furthermore, Behavioral CQ positively moderated the link between long-term orientation and problem solving. While our direct effects of longterm orientation on problem solving style is positive, the moderating results suggests that this association is further enhanced in the presence of Behavioral CQ. Our results demonstrate that choosing appropriate verbal and physical actions when individuals have their eye on the future increased their chances of engaging in problem solving style in managing conflict. This is one of the first few studies to document this important finding of the role of Behavioral CQ in facilitating problem solving style and thereby extending the literature in conflict management.

Additionally, Metacognitive CQ positively moderates the link between power distance and longterm orientation and problem solving style. With power distance, less powerful members of the 
organization expect that power is equally distributed such that in high power distance culture, power is a given and is expected to be used and thus subordinates expect to be told. On the other hand, metacognition represents an ability to strategize when crossing culture and ascertain the thoughts of others (Earley \& Ang, 2003). Previous research suggests that individuals with higher power distance are related to avoiding and forcing (Kim et al., 2007; Purohit \& Simmers, 2006). Our results suggest that individuals who are high in power distance but also with high metacognitive CQ will be involved in high problem solving representing a significant contribution to literature in this area. Similarly, Behavioral CQ positively moderated the link between power distance and forcing style suggesting that individuals high in power distance but also high in behavioral CQ will be involved in increased usage of forcing in managing conflict. This is expected because behavioral CQ is about verbal and physical action while given high power distance, individuals already expect compliance with power. Ultimately, this combination seems to favor the use of forcing as a conflict management.

Motivational CQ positively moderated the link between masculinity and long-term orientation for problem solving. We report earlier that there is a direct effect but negative effect between masculinity and problem solving, however, our moderation results imply that in the presence of Motivational CQ, individuals with high masculine orientation will increasingly be involved in problem solving. Altogether, these results facilitate a better understanding of the dimensions of CQ that are helpful for individuals with masculine orientations in resolving conflict. We also found that Cognitive CQ negatively influence the link between masculinity for forcing suggesting that individuals who have high masculine orientation but also high in Cognitive CQ may engage less in forcing style. Again, this is a new and exciting finding that allows the isolation of the CQ dimensions that may assist in reducing forcing as conflict management style especially if the individual has a masculine orientation.

With regards to the link between cultural orientations, CQ and forcing styles, the findings that Metacognitive CQ, Cognitive CQ and Motivational CQ positively moderated the link between power distance and uncertainty avoidance and forcing are also new. These findings suggest that individuals high in power distance and uncertainly avoidance but also high in Metacognitive CQ (i.e. an ability to 
strategize when crossing culture and ascertain the thoughts of others), Cognitive CQ and Motivational CQ will also have higher chances of engaging in forcing in managing conflict. This may be because of the knowledge of strategies (to use when crossing cultures) and beliefs and norms of a given culture coupled with ability to adapt might give the individuals with power distance, and uncertainty avoidance the confidence to apply force in managing conflict.

\section{Conclusions}

Our study makes several important contributions. Each facet of CQ possesses distinctive traits and characteristics that affect an individual's level of CQ, which in turn, impact the decisions made in conflict situations (Adair et al., 2013; Imai \& Gelfand, 2010). Although the role of CQ in cross-cultural interactions is steadily growing but few studies have investigated the moderating role of CQ in the link between individual cultural orientation and the decision to engage in a specific conflict management style. Most of the research in conflict management adopts a comparative approach in describing and explaining cultural differences among different samples, where culture is usually indirectly measured as nationality or ethnicity. By testing the moderating impact of CQ on conflict management, we go beyond comparing cultural orientations. Specifically, we believe that a more complex and globalized world calls for more nuanced and integrated research approaches with a potential to contribute towards the integration of different cultures and increased effectiveness in cross-cultural interactions.

Our research extends conflict management literature. Our direct effects results confirm that individuals' cultural orientations are key drivers of their conflict management choices. More importantly, our results extend the literature in conflict management. So far, we know that individuals have inclinations (culturally driven) to choose CMSs but what is not known is the effects of CQ on these styles. Our results demonstrate that different dimensions of CQ moderated the link between cultural orientation and differing conflict management styles.

Also, our study has implications for CQ research. CQ is a relatively new concept that depicts some form of cultural competence (Adair et al., 2013) required for effective cross-cultural interactions in global teams and in international business environments. To date, only a few empirical studies exist that 
have examined the moderating role of CQ in the link between cultural orientations and conflict

management style. Our results for example suggest metacognition is important for problem solving if an individual has a power distance orientation while an individual with masculinity orientation will be more

likely to achieve conflict management when he/she possess motivational CQ. In this respect, our study is one of the first few to demonstrate the versatility of CQ in assisting conflict management.

The results of our study have several practical implications. Conflict is pervasive in organizations and while individuals come with a variety of cultural orientation to work, it is the managers' responsibility to ensure that conflict is managed firmly before it has a negative influence on employees' productivity. It is especially important that managers can assist individuals to get to problem solving when there is conflict. Out results suggest that training and understanding the dimensions of CQ will be crucial for managers and employees that are interested in managing conflict effectively. Additionally, individuals come to the organizations with different cultural orientations; this implies that managers who are leading culturally diverse teams need to be aware of their team members' cultural orientations and identity. In this respect, managers should refrain from turning a "blind eye” (O’Leary \& Sandberg, 2017) to their employees' cultural differences, orientations and identities while managing conflict. Altogether managers and leaders who are leading cross-cultural teams will need to train their employees in CQ to minimize relationship challenges presented by cultural differences in organizations.

\subsection{Limitations and directions for further research}

Our study has a number of limitations. First, this is a single sample study and we collected our data from participants through panel service. A large majority of the sample came from the UK and are Anglo-Saxons. This may explain why some of our results were not in the direction predicted.

Nevertheless, our sample size of 403 is robust and encompasses participants from all cultural orientations suggesting the validity of our results. Also, we adopted a self-report approach for data collection. Selfreport is prone to challenges such as common method bias. However, we took several steps (e.g.

collecting the data at two stages, and carried out robustness checks such as Harman one-factor method) to ascertain that the presence of biases in the data did not undermine the validity of our results. Our data 
showed no evidence of common method bias increasing the validity of our results. Altogether, the robustness of our sample, results of the manipulation checks for common method bias and the adoption of scales with adequate long standing reliability and validity contribute to strengthen the validity of our results. Future research should source data from real time individuals in organizations. Also, our study is cross sectional, future studies should examine a longitudinal effect of CQ in the relationship between individual cultural orientations and conflict management styles. 


\section{References}

Adair, W. L., Hideg, I., \& Spence, J. R. (2013). The Culturally Intelligent Team The Impact of Team Cultural Intelligence and Cultural Heterogeneity on Team Shared Values. Journal of Cross-Cultural Psychology, 44(6), 941-962.

Aiken, L. S., West, S. G., \& Reno, R. R. (1991). Multiple regression: Testing and interpreting interactions. London, UK: Sage.

Alper, S., Tjosvold, D., \& Law, K. S. (2000). Conflict management, efficacy, and performance in organizational teams. Personnel Psychology, 53(3), 625-642.

Amason, A. C., \& Schweiger, D. M. (1997). The Effects of Conflict on Strategic Decision Making Effectiveness and Organizational. Using Conflict in Organizations, 101.

Ang, S., Van Dyne, L., Koh, C., Ng, K. Y., Templer, K. J., Tay, C., \& Chandrasekar, N. A. (2007). Cultural intelligence: Its measurement and effects on cultural judgment and decision making, cultural adaptation and task performance. Management and Organization Review, 3(3), 335-371.

Aycan, Z., \& Gelfand, M. J. (2012). Cross-cultural organizational psychology. The Oxford Handbook of Organizational Psychology. New York: Oxford University.

Ayoko, O. B., \& Härtel, C. E. J. J. (2006). Cultural diversity and leadership: A conceptual model of leader intervention in conflict events in culturally heterogeneous workgroups. Cross Cultural Management: An International Journal, 13(4), 345-360.

https://doi.org/10.1108/13527600610713431

Ayoko, O. B., \& Konrad, A. M. (2012). Leaders' transformational, conflict, and emotion management behaviors in culturally diverse workgroups. Equality, Diversity and Inclusion: An International Journal, 31(8), 694-724.

Berinsky, A. J., Margolis, M. F., \& Sances, M. W. (2014). Separating the Shirkers from the Workers? Making Sure Respondents Pay Attention on Self-Administered Surveys. American Journal of Political Science, 58(3), 739-753.

Bowerman, B. L., \& O'connell, R. T. (1990). Linear statistical models: An applied approach. 


\section{Brooks/Cole.}

Bradford, K. D., Stringfellow, A., \& Weitz, B. A. (2004). Managing conflict to improve the effectiveness of retail networks. Journal of Retailing, 80(3), 181-195.

Brewer, N., Mitchell, P., \& Weber, N. (2002). Gender role, organizational status, and conflict management styles. International Journal of Conflict Management, 13(1), 78-94.

Byrne, B. M. (2001). Structural equation modeling: Perspectives on the present and the future. International Journal of Testing, 1(3-4), 327-334.

Caputo, A. (2013). A literature review of cognitive biases in negotiation processes. International Journal of Conflict Management, 24(4). https://doi.org/10.1108/IJCMA-08-2012-0064

Caputo, A. (2016). Overcoming judgmental biases in negotiations: A scenario-based survey analysis on third party direct intervention. Journal of Business Research, 69(10). https://doi.org/10.1016/j.jbusres.2016.04.004

Celuch, K., Bantham, J. H., \& Kasouf, C. J. (2011). The role of trust in buyer-seller conflict management. Journal of Business Research, 64(10), 1082-1088.

Chandrasiri, S. (2016). An ideal hospital: Is leading a workforce engagement strategy the key to tackling bullying, harassment and discrimination in surgical practice? Leadership in Health Services, 30(3), 263-271. https://doi.org/doi.org/10.1108/LHS-03-2016-0014

Chen, A. S., Wu, I., \& Bian, M. (2014). The moderating effects of active and agreeable conflict management styles on cultural intelligence and cross-cultural adjustment. International Journal of Cross Cultural Management, 14(3), 270-288.

Dawson, J. F. (2014). Moderation in management research: What, why, when, and how. Journal of Business and Psychology, 29(1), 1-19.

De Dreu, C. K. W., Evers, A., Beersma, B., Kluwer, E. S., \& Nauta, A. (2001). A theory-based measure of conflict management strategies in the workplace. Journal of Organizational Behavior, 22(6), 645-668. https://doi.org/10.1002/job.107

Earley, P. C., \& Ang, S. (2003). Cultural intelligence: Individual interactions across cultures. Stanford, 


\section{CA: Stanford University Press.}

Earley, P. C., Ang, S., \& Tan, J.-S. (2006). CQ: Developing cultural intelligence at work. Stanford, CA: Stanford University Press.

Earley, P. C., \& Gibson, C. B. (2002). Multinational work teams: A new perspective. Mahwah, NJ: Lawrence Erlbaum.

Euwema, M. C., Vliert, E. Van De, \& Bakker, A. B. (2003). Substantive and Relational Effectiveness of Organizational Conflict Behavior. International Journal of Conflict Management, 14(2), 119-139. https://doi.org/10.1108/eb022894

Gabrielidis, C., Stephan, W. G., Ybarra, O., Pearson, V. M. D. S., \& Villareal, L. (1997). Preferred styles of conflict resolution Mexico and the United States. Journal of Cross-Cultural Psychology, 28(6), 661-677.

Gonçalves, G., Gonçalves, G., Reis, M., Reis, M., Sousa, C., Sousa, C., ... Orgambídez-Ramos, A. (2016). Cultural intelligence and conflict management styles. International Journal of Organizational Analysis, 24(4), 725-742.

Groves, K. S., \& Feyerherm, A. E. (2011). Leader cultural intelligence in context: Testing the moderating effects of team cultural diversity on leader and team performance. Group \& Organization Management, 36(5), 535-566. https://doi.org/10.1177/1059601111415664

Groves, K. S., Feyerherm, A., \& Gu, M. (2015). Examining cultural intelligence and cross-cultural negotiation effectiveness. Journal of Management Education, 39(2), 209-243.

Gunkel, M., Schlaegel, C., \& Taras, V. (2016). Cultural values, emotional intelligence, and conflict handling styles: A global study. Journal of World Business, 51(4), 568-585.

Hair, J. F., Sarstedt, M., Pieper, T. M., \& Ringle, C. M. (2012). The use of partial least squares structural equation modeling in strategic management research: a review of past practices and recommendations for future applications. Long Range Planning, 45(5), 320-340.

Hofstede, G. (1980). Culture's Consequences: International Differences in Work-related Values. CrossCultural Research and Methodology series. https://doi.org/10.5465/AME.2004.12689661 
Hofstede, G. (2001). Culture's consequences: Comparing values, behaviors, institutions and organizations across nations. Beverly Hills, CA: Sage.

Hofstede, G. (2011). Dimensionalizing cultures: The Hofstede model in context. Online Readings in Psychology and Culture, 2(1), 8.

Holt, J. L., \& DeVore, C. J. (2005). Culture, gender, organizational role, and styles of conflict resolution: A meta-analysis. International Journal of Intercultural Relations, 29(2), 165-196.

Hu, L., \& Bentler, P. M. (1999). Cutoff criteria for fit indexes in covariance structure analysis: Conventional criteria versus new alternatives. Structural Equation Modeling: A Multidisciplinary Journal, 6(1), 1-55.

Imai, L., \& Gelfand, M. J. (2010). The Culturally Intelligent Negotiator: The Impact of Cultural Intelligence (CQ) on Negotiation Sequences and Outcomes. Organizational Behavior and Human Decision Processes, 112(2), 83-98. https://doi.org/10.1016/j.obhdp.2010.02.001

Kaushal, R., \& Kwantes, C. T. (2006). The role of culture and personality in choice of conflict management strategy. International Journal of Intercultural Relations, 30(5), 579-603. https://doi.org/10.1016/j.ijintrel.2006.01.001

Kim, K., Kirkman, B. L., \& Chen, G. (2008). Cultural intelligence and international assignment effectiveness. In S. Ang \& L. Van Dyne (Eds.), Handbook of cultural intelligence: Theory, measurement, and applications (pp. 71-90). Armonk, NY: M.R. Sharpe.

Kim, T.-Y., Wang, C., Kondo, M., \& Kim, T.-H. (2007). Conflict management styles: the differences among the Chinese, Japanese, and Koreans. International Journal of Conflict Management, 18(1), $23-41$.

Kirkman, B. L., Lowe, K. B., \& Gibson, C. B. (2006). A quarter century of culture's consequences: A review of empirical research incorporating Hofstede's cultural values framework. Journal of International Business Studies, 37(3), 285-320.

Lin, X., \& Germain, R. (1998). Sustaining satisfactory joint venture relationships: The role of conflict resolution strategy. Journal of International Business Studies, 29(1), 179-196. 
Lin, Y. C., Chen, A. S. Y., \& Song, Y. C. (2012). Does your intelligence help to survive in a foreign jungle? The effects of cultural intelligence and emotional intelligence on cross-cultural adjustment. International Journal of Intercultural Relations, 36(4), 541-552. https://doi.org/http://dx.doi.org/10.1016/j.ijintrel.2012.03.001

Liu, L. A., Chua, C. H., \& Stahl, G. K. (2010). Quality of communication experience: definition, measurement, and implications for intercultural negotiations. Journal of Applied Psychology, 95(3), 469.

Mannix, E., \& Neale, M. A. (2005). What differences make a difference? The promise and reality of diverse teams in organizations. Psychological Science in the Public Interest, 6(2), 31-55.

Menard, S. (1995). Applied logistic regression analysis: Sage university series on quantitative applications in the social sciences. Thousand Oaks, CA: Sage.

O’Leary, J., \& Sandberg, J. (2017). Managers' practice of managing diversity revealed: A practice theoretical account. Journal of Organizational Behavior, 38(4), 512-536.

Ogliastri, E., \& Quintanilla, C. (2016). Building cross-cultural negotiation prototypes in Latin American contexts from foreign executives' perceptions. Journal of Business Research, 69(2), 452-458.

Oudenhoven, J. P., Mechelse, L., \& De Dreu, C. K. W. (1998). Managerial conflict management in five European countries: The importance of power distance, uncertainty avoidance, and masculinity. Applied Psychology, 47(3), 439-455.

Podsakoff, P. M., MacKenzie, S. B., Lee, J.-Y., \& Podsakoff, N. P. (2003). Common method biases in behavioral research: a critical review of the literature and recommended remedies. Journal of Applied Psychology, 88(5), 879.

Podsakoff, P. M., \& Organ, D. W. (1986). Self-reports in organizational research: Problems and prospects. Journal of Management, 12(4), 531-544.

Pruitt, D. G., \& Rubin, J. Z. (1986). Social conflict: Escalation, impasse, and resolution. Reding, MA: Addision-Wesley.

Purohit, Y. S., \& Simmers, C. A. (2006). Power distance and uncertainty avoidance: a cross-national 
examination of their impact on conflict management modes. Journal of International Business Research, 5(1), 1.

Templer, K. J., Tay, C., \& Chandrasekar, N. A. (2006). Motivational cultural intelligence, realistic job preview, realistic living conditions preview, and cross-cultural adjustment. Group \& Organization Management, 31(1), 154-173.

Thomas, K. W. (1992). Conflict and conflict management: Reflections and update. Journal of Organizational Behavior, 13(3), 265-274.

Ting-Toomey, S., Gao, G., Trubisky, P., Yang, Z., Soo Kim, H., Lin, S.-L., \& Nishida, T. (1991). Culture, face maintenance, and styles of handling interpersonal conflict: A study in five cultures. International Journal of Conflict Management, 2(4), 275-296.

Ting-toomey, S., \& Kurogi, A. (1998). Facework competence in intercultural conflict: An updated facenegotiation theory. International Journal of Intercultural Relations, 22(2), 187-225. https://doi.org/10.1016/S0147-1767(98)00004-2

Ting-Toomey, S., Yee-Jung, K. K., Shapiro, R. B., Garcia, W., Wright, T. J., \& Oetzel, J. G. (2000). Ethnic/cultural identity salience and conflict styles in four US ethnic groups. International Journal of Intercultural Relations, 24(1), 47-81. https://doi.org/10.1016/S0147-1767(99)00023-1

Ting-Toomey, S., Oetzel, J. G., \& Yee-Jung, K. (2001). Self-construal types and conflict management styles. Communication Reports, 14(2), 87-104.

Tjosvold, D. (2006). Defining conflict and making choices about its management: Lighting the dark side of organizational life. International Journal of Conflict Management, 17, 87-95. https://doi.org/10.1108/10444060610736585

Van De Vliert, E., Euwema, M. C., \& Huismans, S. E. (1995). Managing conflict with a subordinate or a superior: Effectiveness of conglomerated behavior. Journal of Applied Psychology, 80(2), 271. https://doi.org/10.1037/0021-9010.80.2.271

Vlajčić, D., Caputo, A., Marzi, G., \& Dabić, M. (2018). Expatriate Managers' Cultural Intelligence as a Promoter of Knowledge Transfer in Multinational Companies. Journal of Business Research, 
forthcomin.

Wall, J. A., \& Callister, R. R. (1995). Conflict and its management. Journal of Management, 21(3), 515558.

Wheaton, B., Muthen, B., Alwin, D. F., \& Summers, G. F. (1977). Assessing reliability and stability in panel models. Sociological Methodology, 8, 84-136.

Yoo, B., Donthu, N., \& Lenartowicz, T. (2011). Measuring Hofstede's five dimensions of cultural values at the individual level: Development and validation of CVSCALE. Journal of International

Consumer Marketing, 23(3-4), 193-210.

\section{Authors' biographies}

Andrea Caputo is Reader in Entrepreneurship at the Lincoln International Business School (UK). He received his $\mathrm{PhD}$ in Management from the University of Rome Tor Vergata. He has also been a Visiting scholar at the University of Queensland Business School, at The George Washington School of Business, the University of Sevilla, the University of Alicante, and at the University of Pisa. His main research interests are related to entrepreneurship, negotiation, decision-making, and strategic management. He published more than 30 papers in several international journals, including JBR, BPMJ, EBR, IJEBR and IJCMA among others.

Oluremi B. Ayoko is Associate Professor of Management in the UQ Business School at the University of Queensland, Australia. Remi's principal research interests include conflict management, emotions, leadership, diversity, team work and employee physical work environment and territoriality. The results of her cutting-edge research have been presented in several international and national conferences. Remi is an award-winning researcher and has published in reputable journals such as JOB, APIR, IJCMA, and SGR. She has also written many book chapters and co-edited a Handbook of Conflict Management Research published by Edward Edgar Publishers. Remi is an Associate Editor of the Journal of Management and Organization.

Nii Amoo is Senior Lecturer at Leeds Beckett University. He received his $\mathrm{PhD}$ in Management from the Leeds University Business School. Nii works with the Doctoral community in a number of ways - by being a Lead Facilitator in the Research Training Programme, specifically for Quantitative Research Methods and Mixed Methods Research; the Supervision of PhD/DBA students; the review of doctoral thesis; and Internal \& External examiner of PhD/DBA thesis. Nii's research interest are mainly in strategy and leadership with particularly emphasis on Implementation and in the context of SMEs and Family Businesses. His research work has been presented in a number of international conferences including the British Academy of Management and the Academy of Management. Nii Research work has also been published in a number of international journals, including the Journal of Management Inquiry (JMI), International Journal of Sustainable Strategic Management (IJSSM), and Management Control. He is also an Article Editor for Sage Publications. 